\title{
Nasal packing with bupivacaine during nasotracheal intubation can reduce intubation-related epistaxis
}

\author{
Ho Kyung Yu ${ }^{1}$, Jiyoung Park², Young-Hoon Kang ${ }^{3}$, Hee Bin Park², Sung Il Bae ${ }^{4}$, Soo Hee Lee ${ }^{1}$, Seong-Ho Ok ${ }^{5}$, Sang-Ho Jeong ${ }^{6}$, \\ and Miyeong Park ${ }^{1 \star}$
}

${ }^{1}$ Clinical Assistant Professor, Department of Anesthesiology and Pain Medicine, Gyeongsang National University Changwon Hospital, Changwon, Republic of Korea ${ }^{2}$ Doctor, Department of Anesthesiology and Pain Medicine, Gyeongsang National University Changwon Hospital, Changwon, Republic of Korea ${ }^{3}$ Professor, Department of Dental Surgery, Gyeongsang National University Changwon Hospital, Changwon, Republic of Korea

${ }^{4}$ Clinical Assistant Professor, Department of Anesthesiology and Pain Medicine, Gyeongsang National University Hospital, Jinju, Republic of Korea ${ }^{5}$ Associate Professor, Department of Anesthesiology and Pain Medicine, Gyeongsang National University Changwon Hospital, Changwon, Republic of Korea

${ }^{6}$ Professor, Department of Surgery, Gyeongsang National University Changwon Hospital, Changwon, Republic of Korea

Epistaxis often is caused by nasal mucosal damage and vascular injury after nasotracheal (NT) intubation. Bupivacaine constricts blood vessels at low concentrations and dilates them at high concentrations. In this study, in which we evaluated the effects of intranasal packing with bupivacaine to prevent epistaxis and pain induced by NT intubation, we classified 180 patients into three groups: an untreated group $(n=60)$, a group pretreated with epinephrine $(n=60)$, and a group pretreated with bupivacaine ( $n=60)$. In all groups, we used nasal Ring-Adair-Elwyn tubes with the thermosoftening method for NT intubation. We classified the degree of epistaxis as Grade 0 (none), Grade 1 (mild), Grade 2 (moderate), or Grade 3 (severe). We assessed postoperative visual analog scale (VAS) scores for nose pain in the recovery room. We found that the incidence of epistaxis in the group pretreated with bupivacaine was significantly less than was that of the untreated group $(55 \%$ vs. $35 \%, p<0.05)$. Univariate logistic regression analysis revealed a reduction in epistaxis with bupivacaine nasal packing (odds ratio $=0.689,95 \%$ confidence interval $=0.478,0.992$ ). Postoperative VAS scores after 30 minutes in the nasal area were lower in the group pretreated with bupivacaine than were those in the untreated group or the group pretreated with epinephrine $(p<0.05)$. Therefore, we conclude that nasal packing with bupivacaine can help reduce epistaxis and nasal pain more effectively as compared to cases without pretreatment with this anesthetic.

Key Words: Bupivacaine; Epistaxis; Intubation; Nasal mucosa; Pain

(c) This is an open-access article distributed under the terms of the Creative Commons Attribution Non-Commercial License (http://creativecommons.org/licenses/by-nc/4.0) which permits unrestricted noncommercial use, distribution, and reproduction in any medium, provided the original work is properly cited.

\section{Introduction}

Nasotracheal (NT) intubation is performed in patients with trismus in whom orotracheal intubation is difficult, or in those scheduled for intraoral or oropharyngeal opera- tions. NT intubation can cause epistaxis, bacteremia, tube obstruction, mucosal damage, and nasal discomfort [1,2]. Epistaxis, is the most common complication of NT intubation, and its incidence has been previously reported to range from $22 \%$ to $77 \%$ [3,4]. Generally, epistaxis resolves

Received June 22, 2021; Accepted July 20, 2021

*Corresponding author: Miyeong Park, Department of Anesthesiology and Pain Medicine, Gyeongsang National University Changwon Hospital, 11 Samjeongja-ro, Seongsan-gu, Changwon 51472, Republic of Korea.

Tel: +82-55-214-3342, Fax: +82-55-214-3269, E-mail: mypark93547@gmail.com 
spontaneously or only cause in minor nasal discomfort to the patients postoperatively. However, in severe epistaxis cases, it embarrasses successful completion of NT intubation, and is hard to adequate ventilation, and leads to lifethreatening complication sometimes [5]. Several methods (pre-anesthetic evaluation, pre-treatment with drug, preparation of tube, nostril selection, intubation technique, etc.) have been proposed to avoid these serious complications such as epistaxis [1,4,6-13].

In the pretreatment of nasal passage, a vasoconstrictor (xylometazoline, phenylephrine, cocaine, epinephrine, etc.) is administered for absorption through the nasal mucosa in the form of nasal packing. Nasal packing with a vasoconstrictor ensures vasoconstriction and volume reduction of the submucosal tissue and allows the insertion and easy passage of an NT tube [6,14]. However, the use of vasoconstrictors for nasal pretreatment can cause adverse effects associated with epinephrine-induced tachycardia, especially in patients with cardiovascular disease [15]. The use of aminoamide local anesthetics, such as bupivacaine can further decrease the incidence of epistaxis by reducing the mucosal tissue volume by constriction of the blood vessels supplying the nasal mucosa [16] and can also help to maintain a stable vital sign with analgesic effect. Therefore, in view of the previous studies, we tested the hypothesis that topical application of bupivacaine would reduce epistaxis occurring due to NT intubation.

The purpose of this study was to evaluate the efficacy of bupivacaine pretreatment to reduce epistaxis and nasal pain compared with epinephrine pretreatment or no pretreatment in patients scheduled for NT intubation.

\section{Materials and Methods}

This study was approved by the Institutional Review Board (IRB) of Gyeongsang National University Changwon Hospital (GNUHIRB-2017-02-008). We obtained written informed consent from the patients preoperatively. We enrolled patients who were referred for general anesthesia for dental surgery from January 2017 to December 2017. Inclusion criteria were patients with American Society of Anesthesiologists physical status of 1-2; age, 18 years or older, but younger than 80 years; and judged by the treating physician to be free of any airway abnormality. Patients with expected difficult intubation, uncontrolled hypertension, hematologic abnormality, those on antiplatelet or anticoagulant therapy, a history of nasal surgery or damage to the nasal mucosa, and those in whom NT intubation was attempted more than once were excluded (Fig. 1).

Anesthesiologist alternately used methods no pretreatment, epinephrine, and bupivacaine. After that, we divided into 3 groups and analyzed them.

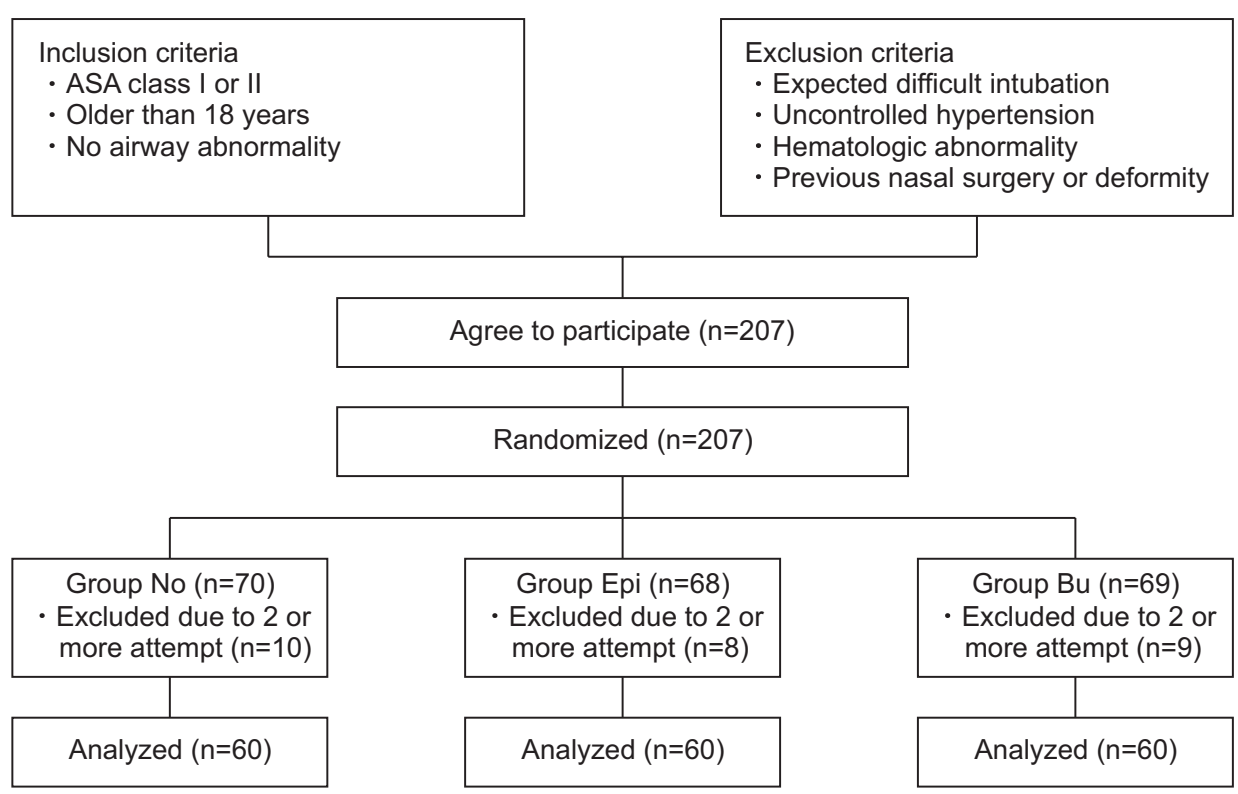

Fig. 1. Flow chart of study. ASA, American Society of Anesthesiologists; Epi, epinephrine; $\mathrm{Bu}$, bupivacaine. 
All Ring-Adair-Elwyn (RAE) nasal tubes (Murphy Eye, Mallinckrodt; Covidien, Mansfield, MA, USA) were prepared as described Kim et al. [7] with 30 minutes of pretreatment in hot water around $45^{\circ} \mathrm{C}$. In the epinephrine and bupivacaine group, the surgical sponges were soaked in $5 \mathrm{~mL}$ of $0.1 \%$ epinephrine or $5 \mathrm{~mL}$ of $0.5 \%$ bupivacaine hydrochloride and packed intranasally. The control group did not use intranasal packing. For blinding, one anesthesiologist prepared the nasal sponges for pretreatment and selected the nostril for packing by reviewing the preoperative medical history and computed tomographic finding. Thereafter, another anesthesiologist performed the NT intubation.

On admission into the operating room, patients' blood pressure and heart rate were checked and they were ventilated with $6 \mathrm{~L} / \mathrm{min}$ of oxygen for 5 minutes via an oxygen mask and then infused with propofol $(1.5-2 \mathrm{mg} / \mathrm{kg}$ ) and remifentanil $(0.1 \mu \mathrm{g} / \mathrm{kg} / \mathrm{min})$ for induction of anesthesia. After ensuring adequate manual ventilation, on the nose to be intubated the nasal packing was performed. And then rocuronium bromide $(0.6 \mathrm{mg} / \mathrm{kg})$ was injected.

First, we checked for the presence of nasal septum deviation and nasal polyps with a facial computed tomography scan preoperatively; if a difference was apparent between the nostrils, nasal packing was performed by choosing a location where the nasal cavity was wide. If the macroscopic differences between the space of nasal cavities were unclear, the right nostril was chosen [17], and then, the patients were ventilated with sevoflurane (minimum alveolar concentration of 3-4 vol\%) for 5 minutes.

When adequate muscle relaxation was achieved 5 minutes after rocuronium injection, NT intubation was performed using a lubricated nasal RAE tube. Generally, the nasal passage will permit use of a tube $1 \mathrm{~mm}$ diameter smaller than used for oral intubation $[7,18]$. After intubation, blood pressure and heart rate were recorded again. Anesthesia was performed by two trained anesthesiologists with more than 10 years of experience.

The primary end point of this study was to assess the extent of epistaxis during NT intubation. The extent of epistaxis was confirmed by the intubating anesthesiologist and the severity was determined according to the degree of bleeding after intubation; no bleeding=no epistaxis; blood only on endotracheal tube=mild epistaxis; indicated blood pooling in the pharynx=moderate epistaxis; and represented blood in the pharynx sufficient to impede intubation=severe epistaxis [19]. The degree of navigability through the nasal passageways was defined as smooth or impinged. The patient was examed for nasal pain by assessment of visual analog scale score in the recovery room, after 30 minutes postoperatively.

For the statistical analysis, an analysis of variance test was performed using the SPSS software (version 24.0; IBM corp., Armonk, NY, USA) and Scheffé's test was used as the post-hoc test. $p$-values $<0.05$ was considered statistically significant. Data are expressed as mean \pm standard deviation.

\section{Results}

The mean age of the patients was $39.4 \pm 16.8$ years; 115 (63.9\%) patients were men and 65 (36.1\%) were women. Their mean height was $166.5 \pm 8.5 \mathrm{~cm}$; the mean body weight was $65.6 \pm 12.2 \mathrm{~kg}$, and the mean tube size used was $6.728 \pm 0.3 \mathrm{~mm}$. The right nostril was used for NT intubation in 134 patients and the left nostril was used in 46 patients. There were 105 cases without navigability and 75 cases with navigability; the average surgical duration was 80.8 minutes (Table 1 ).

Of the 60 patients in the control group, 42 (70.0\%) had either no or mild bleeding, 14 (23.3\%) had moderate bleeding, and $4(6.7 \%)$ had severe bleeding. Of the 60 patients in the epinephrine group, 51 (85.0\%) had no or mild bleeding, 9 (15.0\%) had moderate bleeding, and no patient (0\%) had severe bleeding. Of the 60 patients in the bupivacaine group, $52(86.7 \%)$ had either no or mild bleeding, 8 (13.3\%) had moderate bleeding, and no patient $(0 \%)$ had severe bleeding (Fig. 2). The visual analog scale score in the recovery room was significantly lower in the bupivacaine group (3.2 \pm 1.1$)$ than that in the epinephrine $(3.7 \pm 1.2)$ and the control groups (3.7 $\pm 1.0, p=0.031$; Fig. 3 ).

Comparison of heart rate and systolic blood pressure on admission into the operating room and after intubation; showed that the proportion of patients with increased heart rate was lower in the bupivacaine group, and moreover, patients in this group had reduced blood pressure. The mean values of heart rate after arrival in the operating 
Table 1. Demographic characteristics of the patients

\begin{tabular}{llccc}
\hline \multicolumn{1}{c}{ Variable } & & Untreated $(\mathbf{n}=\mathbf{6 0})$ & Epinephrine $(\mathbf{n}=\mathbf{6 0})$ & Bupivacaine $(\mathbf{n}=\mathbf{6 0})$ \\
\hline Age $(\mathrm{y})$ & & $37.4 \pm 14.9$ & $40.0 \pm 16.8$ & $40.0 \pm 18.7$ \\
Sex & Male & 40 & 37 & 38 \\
& Female & 20 & 23 & 22 \\
Height (cm) & & $167.0 \pm 9.4$ & $165.9 \pm 8.3$ & $166.5 \pm 8.0$ \\
Weight (kg) & & $67.0 \pm 13.9$ & $65.3 \pm 11.6$ & $64.5 \pm 11.0$ \\
Tube size (ID, mm) & & $6.725 \pm 0.3$ & $6.733 \pm 0.3$ & $6.725 \pm 0.3$ \\
Nostril (right/left) & & $44 / 16$ & $46 / 14$ & $44 / 16$ \\
Magil-forceps (yes/no) & Yes & $38 / 22$ & $36 / 24$ & $40 / 20$ \\
Resistance & No & 41 & $36^{*}$ & $28^{*}$ \\
Intubation time (min) & & $92.4 \pm 72.9$ & $70.7 \pm 53.1$ & 32 \\
\hline
\end{tabular}

Values are presented as number only or mean \pm standard deviation.

ID, inner diameter; $n$, number of patients.

${ }^{*} p<0.05$ compared with untreated group.

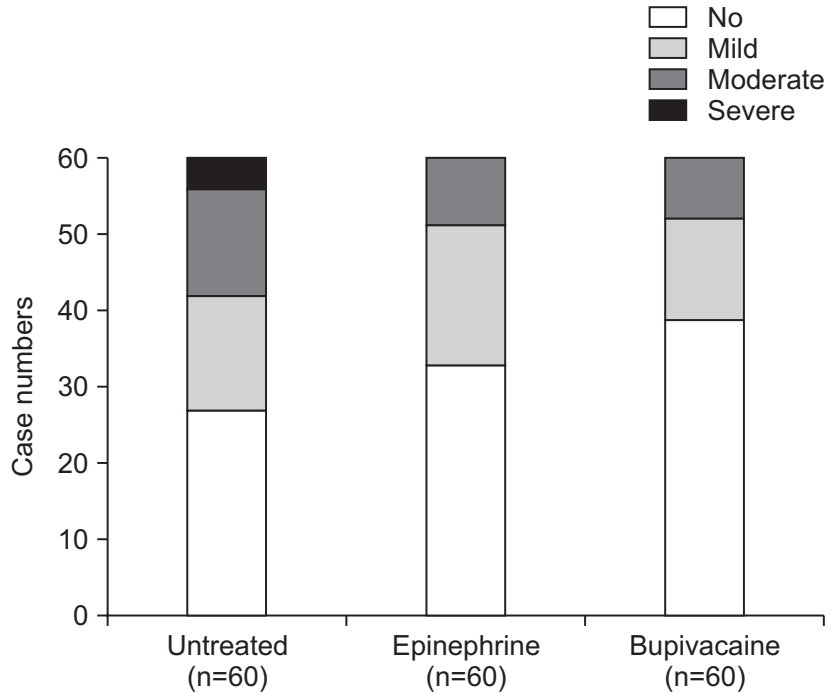

Fig. 2. The incidences of epistaxis in the untreated group, epinephrine group, and bupivacaine group. Bupivacaine and epinephrine groups were significantly lower than untreated group in the incidence of severe epistaxis $(p<0.05)$.

room were $75.3,74.9$, and 77.2 beats/min in the control, epinephrine, and bupivacaine groups, respectively. After intubation were 92.2, 93.8, and 87.7 beats/min, respectively. The systolic blood pressure after arrival in the operating room were $130.2,131.4$, and $132.6 \mathrm{mmHg}$ in the control, epinephrine, and bupivacaine groups, respectively, before intubation. After intubation were 123.8, 123.5, and $113.1 \mathrm{mmHg}$, respectively. Only the patients in the bupivacaine treated group showed significant decrease in systolic blood pressure after NT intubation ( $p=0.049)$, without any

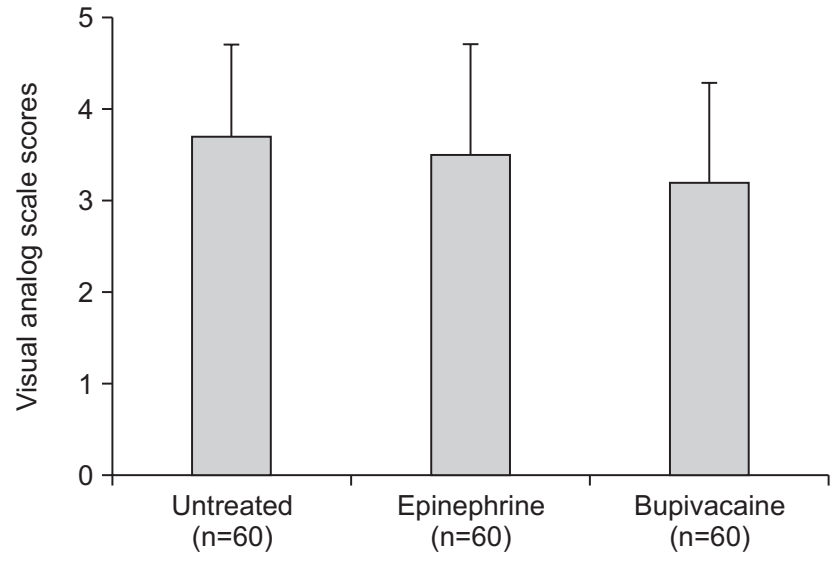

Fig. 3. Visual analog scale scores in the post-anesthesia care unit $(p<0.05)$. The visual analog scale score in the recovery room was statistically significantly lower in the bupivacaine group (3.2 \pm 1.1$)$ than in the epinephrine $(3.7 \pm 1.2)$ and untreated groups $(3.7 \pm 1.0)$. Values are presented as mean \pm standard deviation.

decrease in the magnitude of elevated heart rate $(p=0.076$; Table 2). None of patients had any severe complications, such as uncontrolled postoperative bleeding regarding to NT intubation.

In these results, only bupivacaine packing significantly decreased systolic blood pressure induced by NT intubation $(p=0.049)$, not decreased the magnitude of increased heart rate ( $p=0.076$; Table 2). Univariate logistic regression analysis revealed that epistaxis was reduced with nasal packing of bupivacaine (odds ratio $=0.689 ; 95 \%$ confidence interval $=0.478,0.992$ ), but multivariate logistic regression analysis does'nt show statistically significant (Table 3). 
Table 2. Hemodynamic response to intubation after intubation between the packing groups

\begin{tabular}{|c|c|c|c|c|c|c|}
\hline \multirow{2}{*}{ Variable } & \multicolumn{2}{|c|}{ Untreated $(n=60)$} & \multicolumn{2}{|c|}{ Epinephrine $(n=60)$} & \multicolumn{2}{|c|}{ Bupivacaine $(n=60)$} \\
\hline & Before intubation & After intubation & Before intubation & After intubation & Before intubation & After intubation \\
\hline Heart rate (beats/min) & $75.3 \pm 13$ & $92.2 \pm 15$ & $74.9 \pm 15$ & $93.8 \pm 15$ & $77.2 \pm 16$ & $87.7 \pm 17$ \\
\hline $\mathrm{SBP}(\mathrm{mmHg})$ & $130.2 \pm 16$ & $123.8 \pm 22$ & $131.4 \pm 18$ & $123.5 \pm 23$ & $132.6 \pm 25$ & $113.1 \pm 20^{*}$ \\
\hline
\end{tabular}

Values are presented as mean \pm standard deviation.

SBP, systolic blood pressure.

${ }^{\star} p<0.05$ compared with untreated group.

Table 3. Potential predictors of Epistaxis during nasotracheal intubation between the packing groups by logistic regression analysis

\begin{tabular}{|c|c|c|c|c|c|c|}
\hline \multirow{2}{*}{ Variable } & \multirow{2}{*}{$\begin{array}{c}\text { Epistaxis } \\
(\mathrm{n}=\mathbf{8 1})\end{array}$} & \multirow{2}{*}{$\begin{array}{c}\text { No epistaxis } \\
\quad(n=99)\end{array}$} & \multicolumn{2}{|c|}{$\begin{array}{c}\text { Univariate logistric } \\
\text { regression }\end{array}$} & \multicolumn{2}{|c|}{$\begin{array}{l}\text { Multivariate logistic } \\
\text { regression }\end{array}$} \\
\hline & & & OR & 95\% CI & OR & $95 \%$ CI \\
\hline Nasal packing (No/Epi/Bu) & $33 / 27 / 21$ & $27 / 33 / 39$ & $0.689^{\dagger}$ & $0.47,0.99$ & NS & \\
\hline Age $(38 \mathrm{y} /<38 \mathrm{y})$ & $48 / 35$ & $45 / 52$ & NS & & NS & \\
\hline Sex (male/female) & $52 / 31$ & $62 / 35$ & NS & & NS & \\
\hline Nostril (right/left) & $59 / 24$ & $68 / 29$ & NS & & NS & \\
\hline Tube size (ID, mm: 6.0/6.5/7.0) & $11 / 25 / 47$ & $8 / 32 / 57$ & NS & & NS & \\
\hline Resistance (impinged/smooth) & $62 / 21$ & $45 / 52$ & $6.638^{\ddagger}$ & $2.765,15.939$ & $10.279^{\dagger}$ & $2.143,49.291$ \\
\hline
\end{tabular}

Data are expressed as the number of patients.

$\mathrm{Bu}$, bupivacaine; Epi, epinephrine; ID, inner diameter; OR, odds ratio; 95\% CI, 95\% confidence intervals; NS, not significant.

${ }^{\dagger} p<0.05$ compared with untreated group. ${ }^{\ddagger} p<0.01$ compared with untreated group.

\section{Discussion}

Our study was designed to compare pre-treatment drugs on the nasal mucosa for reducing epistaxis during NT intubation. And this is the first study to implying the nasal packing with bupivacaine is an effective pretreatment to reduce the complications of NT intubation despite thermosoftening method. The major findings of this study are as follows: 1) nasal packing with bupivacaine before NT intubation reduced epistaxis more than control group and it was not different with the epinephrine nasal packing group; 2) the nasal packing with bupivacaine reduced nasal pain compared with the epinephrine and control groups; 3) the nasal packing with bupivacaine could attenuate the increase of heart rate induced by NT intubation than that appeared in the epinephrine and control groups; 4) the nasal packing with bupivacaine could maintain the systolic blood pressure lower after nasal intubation than that of the epinephrine and control groups.

In the anatomical point of view, the usual causes of epistaxis after NT intubation is Kiesselbach's plexus injury [18].
These blood vessels are considered capable of reducing epistaxis during intubation if there is proper constriction of the vessels supplying blood to Little's area in the anterior part of the nasal septum. So, the selection of the which nostril more wider than other in physical or radiological examination and the pretreatment of nasal cavity with a vasoconstrictor could more reduce epistaxis induced by NT intubation [4,6,17,20-22].

Vasoconstrictor is absorbed through the mucosa from nasal packing and helps to ensure enough space to allow easy passage of the NT tube through the airway interior from a narrow nose from the reduction in submucosal tissue volume due to vasoconstriction. The nasal cavity was enlarged after vasoconstrictor use; thus, such drugs are used commonly to widen the nasal cavity $[21,23,24]$. Nevertheless, the use of vasoconstrictors to widen the passages in the nasal cavity also conveys the risk of adverse drug reactions, such as arrhythmia, cardiac arrest, and temporary hypertension [14,25-27]. Because of these adverse effect of vasoconstrictors, if possible topical phenylephrine for nasal decongestion was avoided and the topical usage of cocaine 
should be closely monitored [14]. The clinical case report about the usage of topical epinephrine could cause cardiogenic shock in young healthy patient [25] implied that we should choose more safe drug for nasal pretreatment and observe the patients more carefully. Even the thermosoftening method alone reduced the damage of the nasal mucosa but could not be protect mucosal damage perfectly, and the nasal cavity pain induced by NT intubation can cause hypertensive response and epistaxis. It would be better strategy that combined prevention of hypertensive response and decongestion of the nasal mucosa. We interested in the pretreatment of the nasal cavity with bupivacaine as target for reducing epistaxis and nasal discomfort after NT intubation.

Bupivacaine, an aminoamide local anesthetic, has a dosedependent biphasic contractile and relaxant effects on the blood vessels. Low concentration of bupivacaine for clinical local anesthesia enables vasoconstriction and easy absorption and removal of the drug. Therefore, the net effect is prolonged local anesthesia due to the increased elimination half-life of bupivacaine [16,28]. When the intranasal pretreatment with $0.5 \%$ bupivacaine or $0.1 \%$ epinephrine was performed, we could visually observe the widening of nasal cavity and the pale nasal mucosa due to decongestion of the nasal mucosa. But we could not measure the changes of the nasal cavity's space and the nasal mucosa's color between before and after nasal pretreatment with bupivacaine or epinephrine by key metrics.

A previous study reported that topical administration of bupivacaine in pediatric patients for tonsillectomy may have analgesic effect comparable to that of topical lidocaine with epinephrine and moreover, without any of the adverse effect of the latter [29]. This motivated us to treat nasal cavity with $0.5 \%$ bupivacaine before NT intubation in this study. However, at high concentrations and toxic doses, bupivacaine can cause local anesthetic systemic toxicity (LAST), which leads to systemic toxicity due to vascular relaxation and severe cardiovascular dysfunction, such as suppression of cardiac contractility. The cardiotoxic concentration of bupivacaine, was $2.25 \mu \mathrm{g} / \mathrm{mL}$ in the plasma of healthy volunteer [30], and the maximal plasma concentration of bupivacaine in a patient who had a 50 $\mathrm{mg}$ bupivacaine lozenge for severe mucositis was $600 \mathrm{ng} /$
$\mathrm{mL}$ [31], approximately quarter of the cardiotoxic dose reported by the former study [30]. In this study, $25 \mathrm{mg}$ of bupivacaine was administered topically, half the dose the reported previously (bupivacaine lozenge study) [31]. In addition, bupivacaine is absorbed much more slowly through the nasal mucosa than that by rapid intravenous infusion, and moreover, it is distributed evenly by the blood circulation. Therefore, it is considered to be safer than local injection of a vasoconstrictor, which is mainly used in intranasal endoscopic surgery $[32,33]$. However, we closely monitored the patients treated nasal cavity with bupivacaine or epinephrine and prepared 20\% intralipid to promptly treat the occurrence of LAST. There was no adverse response to pretreatment of nasal cavity with $0.5 \%$ bupivacaine in this study.

The use of local anesthetic, bupivacaine, will be extremely cost-effective, and simple nasal packing with the optimal dose of the drug can achieve both a tissue volume reduction due to its vasoconstrictive effect and an analgesic effect. These results suggest that intranasal packing with bupivacaine can reduce nasal bleeding during NT intubation, and therefore, can be used an alternative drug to epinephrine for use in patients with coronary artery disease; to obviate the possible cardiac complication.

In our study, pretreatment with bupivacaine reduced the number of epistaxis events, by a difference of approximately $6 \%-15 \%$. Therefore, the effect of bupivacaine pretreatment on epistaxis might not have been significant in the thermosoftening method used in current study. However, this study showed that nasal packing of bupivacaine, a widely used topical anesthetic, can be used without the inconvenience of application when the patient was awake, could be performed by nasal packing for 5 minutes during muscle relaxation. We believe that the nasal pretreatment with bupivacaine is a preferable alternative to existing methods to reduce epistaxis and nasal pain associated with NT intubation. Our study showed minor difference of epistaxis $(<15 \%)$, so we need more research.

\section{Conflicts of Interest}

The authors declare that they have no competing interests. 


\section{ORCID}

\author{
Ho Kyung Yu \\ https://orcid.org/0000-0001-6986-9394 \\ Jiyoung Park \\ https://orcid.org/0000-0001-5028-2032 \\ Young-Hoon Kang \\ https://orcid.org/0000-0002-7245-2773 \\ Hee Bin Park \\ https://orcid.org/0000-0002-0917-8724 \\ Sung Il Bae \\ https://orcid.org/0000-0002-2991-2746 \\ Soo Hee Lee \\ https://orcid.org/0000-0002-6047-633X \\ Seong-Ho Ok \\ https://orcid.org/0000-0002-1292-7108 \\ Sang-Ho Jeong \\ https://orcid.org/0000-0001-9061-6236 \\ Miyeong Park \\ https://orcid.org/0000-0002-2632-3014
}

\section{References}

1. Prasanna D, Bhat S. Nasotracheal intubation: an overview. J Maxillofac Oral Surg 2014;13:366-372. doi: 10.1007/ s12663-013-0516-5.

2. Fletcher R, Olsson K, Helbo-Hansen S, Nihlson C, Hederström P. Oral or nasal intubation after cardiac surgery? A comparison of effects on heart rate, blood pressure and sedation requirements. Anaesthesia 1984;39:376-378. doi: 10.1111/j.1365-2044.1984.tb07282.x.

3. Boku A, Hanamoto H, Hirose Y, Kudo C, Morimoto Y, Sugimura M, Niwa H. Which nostril should be used for nasotracheal intubation: the right or left? A randomized clinical trial. J Clin Anesth 2014;26:390-394. doi: 10.1016/ j.jclinane.2014.01.016.

4. Lee JH, Kim CH, Bahk JH, Park KS. The influence of endotracheal tube tip design on nasal trauma during nasotracheal intubation: magill-tip versus murphy-tip. Anesth Analg 2005;101:1226-1229, table of contents. doi: 10.1213/01.ane.0000169293.59514.28.

5. Piepho T, Thierbach A, Werner C. Nasotracheal intubation: look before you leap. Br J Anaesth 2005;94:859-860. doi: 10.1093/bja/aei146.

6. El-Seify ZA, Khattab AM, Shaaban AA, Metwalli OS, Hassan HE, Ajjoub LF. Xylometazoline pretreatment reduces nasotracheal intubation-related epistaxis in paediatric dental surgery. Br J Anaesth 2010;105:501-505. doi: 10.1093/bja/ aeq205.

7. Kim YC, Lee SH, Noh GJ, Cho SY, Yeom JH, Shin WJ, Lee DH, Ryu JS, Park YS, Cha KJ, Lee SC. Thermosoftening treatment of the nasotracheal tube before intubation can reduce epistaxis and nasal damage. Anesth Analg 2000;91:698-701. doi: 10.1097/00000539-20000900000038.

8. Takasugi Y, Futagawa K, Konishi T, Morimoto D, Okuda T. Possible association between successful intubation via the right nostril and anatomical variations of the nasopharynx during nasotracheal intubation: a multiplanar imaging study. J Anesth 2016;30:987-993. doi: 10.1007/s00540016-2253-7.

9. Seo KS, Kim JH, Yang SM, Kim HJ, Bahk JH, Yum KW. A new technique to reduce epistaxis and enhance navigability during nasotracheal intubation. Anesth Analg 2007;105:1420-1424, table of contents. doi: 10.1213/01. ane.0000281156.64133.bd.

10. Kwon MA, Song J, Kim S, Ji SM, Bae J. Inspection of the nasopharynx prior to fiberoptic-guided nasotracheal intubation reduces the risk epistaxis. J Clin Anesth 2016;32:711. doi: 10.1016/j.jclinane.2015.12.016.

11. Earle R, Shanahan E, Vaghadia H, Sawka A, Tang R. Epistaxis during nasotracheal intubation: a randomized trial of the Parker Flex-Tip ${ }^{\mathrm{MM}}$ nasal endotracheal tube with a posterior facing bevel versus a standard nasal RAE endotracheal tube. Can J Anaesth 2017;64:370-375. doi: 10.1007/ s12630-017-0813-4.

12. Sugiyama K, Takahashi N, Kohjitani A. The EndoFlex tube enhances navigability through the nasal cavity during nasotracheal intubation. Anesth Analg 2009;108:1358-1359. doi: 10.1213/ane.0b013e318197c905.

13. Xue F, Zhang G, Liu J, Li X, Sun H, Wang X, Li C, Liu K, $\mathrm{Xu} \mathrm{Y}$, Liu Y. A clinical assessment of the Glidescope videolaryngoscope in nasotracheal intubation with general anesthesia. J Clin Anesth 2006;18:611-615. doi: 10.1016/ j.jclinane.2006.03.018.

14. Higgins TS, Hwang PH, Kingdom TT, Orlandi RR, Stammberger H, Han JK. Systematic review of topical vasoconstrictors in endoscopic sinus surgery. Laryngoscope 2011;121:422-432. doi: 10.1002/lary.21286.

15. Middlehurst RJ, Gibbs A, Walton G. Cardiovascular risk: the safety of local anesthesia, vasoconstrictors, and sedation in heart disease. Anesth Prog 1999;46:118-123.

16. Sung HJ, Ok SH, Sohn JY, Son YH, Kim JK, Lee SH, Han JY, Lim DH, Shin IW, Lee HK, Chung YK, Choi MJ, Sohn JT. Vasoconstriction potency induced by aminoamide local anesthetics correlates with lipid solubility. J Biomed Biotechnol 2012;2012:170958. doi: 10.1155/2012/170958.

17. Sanuki T, Hirokane M, Kotani J. Epistaxis during nasotracheal intubation: a comparison of nostril sides. J Oral Maxillofac Surg 2010;68:618-621. doi: 10.1016/ 
j.joms.2009.04.097.

18. Dauphinee K. Nasotracheal intubation. Emerg Med Clin North Am 1988;6:715-723. doi: 10.1016/S07338627(20)30523-X.

19. Katz RI, Hovagim AR, Finkelstein HS, Grinberg Y, Boccio RV, Poppers PJ. A comparison of cocaine, lidocaine with epinephrine, and oxymetazoline for prevention of epistaxis on nasotracheal intubation. J Clin Anesth 1990;2:16-20. doi: 10.1016/0952-8180(90)90043-3.

20. Rector FT, DeNuccio DJ, Alden MA. A comparison of cocaine, oxymetazoline, and saline for nasotracheal intubation. AANA J 1987;55:49-54.

21. Kameyama K, Watanabe S, Kano T, Kusukawa J. Effects of nasal application of an epinephrine and lidocaine mixture on the hemodynamics and nasal mucosa in oral and maxillofacial surgery. J Oral Maxillofac Surg 2008;66:2226-2232. doi: 10.1016/j.joms.2008.01.013.

22. O'Hanlon J, Harper KW. Epistaxis and nasotracheal intubation--prevention with vasoconstrictor spray. Ir J Med Sci 1994;163:58-60. doi: 10.1007/BF02943016.

23. Han JS, Park SH, Shin YD, Kwon E, Shim WS, Bae JH. The effect of xylometazoline spray for expansion of nasal cavity. Korean J Anesthesiol 2013;65:132-135. doi: 10.4097/ kjae.2013.65.2.132.

24. Cole P, Haight JS, Cooper PW, Kassel EE. A computed tomographic study of nasal mucosa: effects of vasoactive substances. J Otolaryngol 1983;12:58-60.

25. Schwalm JD, Hamstra J, Mulji A, Velianou JL. Cardiogenic shock following nasal septoplasty: a case report and review of the literature. Can J Anaesth 2008;55:376-379. doi: 10.1007/BF03021494.

26. Yang JJ, Zheng J, Liu HJ, Liu YX, Shen JC, Zhou ZQ. Epinephrine infiltration on nasal field causes significant hemodynamic changes: hypotension episode monitored by impedance-cardiography under general anesthesia. J Pharm Pharm Sci 2006;9:190-197.
27. Janjua M, Badshah A, Allen SA. Images in cardiology. Epinephrine-induced ST elevation: a case of endobronchial topical epinephrine-induced coronary vasospasm. Heart 2009;95:656. doi: 10.1136/hrt.2008.161646.

28. Ok SH, Sohn JT, Baik JS, Kim JG, Park SS, Sung HJ, Shin MK, Kwon YH, Park CS, Shin IW, Lee HK, Chung YK. Lipid emulsion reverses Levobupivacaine-induced responses in isolated rat aortic vessels. Anesthesiology 2011;114:293301. doi: 10.1097/ALN.0b013e3182054d22.

29. Ozmen OA, Ozmen S. Topical bupivacaine compared to lidocaine with epinephrine for post-tonsillectomy pain relief in children: a randomized controlled study. Int J Pediatr Otorhinolaryngol 2011;75:77-80. doi: 10.1016/ j.ijporl.2010.10.013.

30. Bardsley H, Gristwood R, Baker H, Watson N, Nimmo W. A comparison of the cardiovascular effects of levobupivacaine and rac-bupivacaine following intravenous administration to healthy volunteers. Br J Clin Pharmacol 1998;46:245-249. doi: 10.1046/j.1365-2125.1998.00775.x.

31. Mogensen S, Sverrisdóttir E, Sveinsdóttir K, Treldal C, Jensen K, Jensen AB, Kristensen CA, Jacobsen J, Kreilgaard M, Petersen J, Andersen O. Absorption of bupivacaine after administration of a lozenge as topical treatment for pain from oral mucositis. Basic Clin Pharmacol Toxicol 2017;120:71-78. doi: 10.1111/bcpt.12644.

32. Yilmaz S, Demiraran Y, Akkan N, Yaman H, Iskender A, Güçlü E, Oztürk O. The effects of topical levobupivacaine on morbidity in pediatric tonsillectomy patients. Int J Pediatr Otorhinolaryngol 2009;73:1208-1210. doi: 10.1016/ j.ijporl.2009.05.006.

33. Haytoğlu S, Kuran G, Muluk NB, Ar 1 kan OK. Different anesthetic agents-soaked sinus packings on pain management after functional endoscopic sinus surgery: which is the most effective? Eur Arch Otorhinolaryngol 2016;273:1769-1777. doi: 10.1007/s00405-015-3807-2. 